\title{
Recommendation of RILEM TC237-SIB: protocol for characterization of recycled asphalt (RA) materials for pavement applications
}

\author{
Gabriele Tebaldi (D) Eshan V. Dave - Augusto Cannone Falchetto • \\ Martin Hugener • Daniel Perraton • Andrea Grilli • Davide Lo Presti • \\ Marco Pasetto · Andreas Loizos · Kim Jenkins · Alex Apeagyei • \\ James Grenfell • Maurizio Bocci
}

Received: 9 May 2018/ Accepted: 8 September 2018/Published online: 18 October 2018

(C) RILEM 2018

\begin{abstract}
This recommendation proposes an experimental protocol to characterize recycled asphalt materials. The guidelines presented in this document are based on the results of a round robin test organized by the RILEM Technical Committee 237-SIB “Testing and characterization of sustainable innovative bituminous materials and systems" and provide
\end{abstract}

Contributors Elie Hajj, Patrick Muraya, Giovanni Giacomello, Di Wang.

This recommendation was developed by the task group TG6 within RILEM TC 237-SIB consisting of Gabriele Tebaldi, Eshan Dave, Martin Hugener, Augusto Cannone Falchetto, Daniel Perraton, Andrea Grilli, Davide Lo Presti, Marco Pasetto, Andreas Loizos, Kim Jenkins, Alex Apeagyei, James Grenfell, Maurizio Bocci. The draft recommendation was submitted for approval to the full TC and subsequently approved by RILEM TC 237-SIB.

TC Chairman: Manfred N. Partl (EMPA-Swiss Federal Laboratories for Materials Science and Technology, Dubendorf, Switzerland).

TC Secretary: Emmanuel Chailleux (IFSTTAR-French institute of science and technology for transport, development and networks, Nantes, France).

TG6 Group Leader: Gabriele Tebaldi (University of Parma, Italy-University of Florida, USA).

TC Members: Gordon Airey (UK), Alex Apeagyei (UK), Ignacio Artamendi (UK), Hassan Baaj (Canada), Hussain U. Bahia (USA), Wojciech Bankowski (Poland), Davide Broere (The Netherlands), Maurizio Bocci (Italy), Yves Brosseaud (France), Willam G. Buttlar (USA), Francesco Canestrari (Italy), Armelle Chabot (France), Emmanuel Chailleux information on the testing procedure, data analysis and indications for the preparation of a test report.

Keywords Recycled asphalt (RA) - Round robin test (RRT) · Testing protocol

(France), Eshan Dave (USA), Joëlle De Visscher, (Belgium), Hervé Di Benedetto (France), Augusto Cannone Falchetto (Germany), Gilda Ferrotti (Italy), Tomas Gabet (France), Marcin Gajewski (Poland), Vincent Gaudefroy (France), William Grady (The Netherlands), Andrea Graziani (Italy), James Grenfell (UK), Andrea Grilli (San Marino), Ferhat Hammoum (France), Bernhard Hofko (Austria), Martin Hugener(Switzerland), Illan Ishai (Israel), Kim Jenkins (South Africa), Nicole Kringos (Sweden), Greet A.Leegwater (The Netherlands), Eyal Levenberg (Israel), Andreas Loizos (Greece), Davide Lo Presti (UK), Xiaohu Lu (Sweden), Paul Marsac (France), Anne Millien (France), Konrad Mollenhauer (Germany), Francisco Morea (Argentina), Virginie Mouillet (France), Patrick Muraya (Norway), Marco Pasetto (Italy), Manfred N. Partl(Switzerland), Daniel Perraton (Canada), Christophe Petit (France), Katherine Petros (USA), Laurent Porot (The Netherlands), Simon Pouget (France), Lily D. Poulikakos (Switzerland), Christiane Raab (Switzerland), Safwat Said (Sweden), Cesare Sangiorgi (Italy), Cédric Sauzéat (France), Tom Scarpas (The Netherlands), Hilde Soenen (Belgium), Dariusz Sybilsky (Poland), Gabriele Tebaldi (Italy), Ann Vanelstraete (Belgium), Stefan Vansteenkiste (Belgium), Michael Wistuba (Germany), Ludo Zanzotto (Canada), Adam Zofka (Poland). 


\section{Introduction}

Reclaimed asphalt (RA) is currently one of the most recycled materials in the pavement construction industry [1]. This is strictly associated with the need of implementing efficient and effective maintenance plans of the existing road network while preserving precious and non-renewable natural resources. Currently, different recycling techniques are available depending on the mixing temperature; cold, warm, half-warm or hot recycling. In spite of this difference in production techniques, RA is commonly classified and managed similarly to natural aggregates, frequently without a precise consideration of potential effects due to aged bitumen contained in the RA material. In addition, RA presents a high degree of heterogeneity making very complex to obtain, during the construction process, the same material characteristics achieved during the design phase.

A robust and simple characterization protocol for RA is therefore very much needed. Such a characterization method is critical for providing quality assurance and quality control for the design of recycled mixtures, together with specific information from the bitumen related characteristic of the RA. In addition, a new characterization procedure should be capable of being easily implemented on a routine basis for practitioners in road authorities and department of

G. Tebaldi ( $\square)$

University of Parma, Parma, Italy

e-mail: gtebaldi@unipr.it

G. Tebaldi

University of Florida, Gainesville, USA

E. V. Dave

Civil and Environmental Engineering, University of New Hampshire, New Hampshire, USA

A. Cannone Falchetto

Technische Universitat Braunschweig, Braunschweig, Germany

\section{Hugener}

EMPA Swiss Federal Laboratories for Materials Science and Technology, Dübendorf, Switzerland

D. Perraton

University of Québec, ETS, Montreal, Québec, Canada

A. Grilli

University of San Marino, San Marino, San Marino transportation based on current test methods, which can be quickly performed to finally obtain a fingerprint of the RA material in terms of its use for in-place and plant recycling into asphalt pavements.

\section{Scope}

The present recommendation presents a new characterization procedure for RA materials. This recommendation is based on the results of a round robin test (RRT) organized by the RILEM Technical Committee 237-SIB TG 6 "Testing and characterization of sustainable innovative bituminous materials and systems-Cold Recycling”. This document contains guidelines on material preparation, testing procedure, data analysis and presentation of results.

The application of this characterization procedure is primarily intended for use in new, rehabilitated and maintenance related construction activities for asphalt pavements. The proposed protocol is specifically focused towards road owner agencies, road management agencies and road constructors. The main purpose of this characterization procedure is to develop a fingerprint method for RA materials and to determine and obtain parameters that can enhance the reliability of design procedures for asphalt mixture.

\author{
D. Lo Presti \\ University of Nottingham, Nottingham, UK \\ M. Pasetto \\ University of Padova, Padova, Italy
}

A. Loizos

National Technical University of Athens, Athens, Greece

K. Jenkins

Stellenbosch University, Stellenbosch, South Africa

A. Apeagyei

University of East London, London, UK

J. Grenfell

Australian Road Research Board, Melbourne, Australia

M. Bocci

Università Politecnica Delle Marche, Ancona, Italy 


\section{Referenced documents}

The following section provides a list of international standards and documents linked to the present recommendation.

\subsection{RA material}

Particle size distribution (black curve)

- ASTM C136/C136 M-14 (2014) Standard test method for sieve analysis of fine and coarse aggregates, ASTM International, West Conshohocken, PA.

- EN 933-1 (2012) Tests for geometrical properties of aggregates-part 1: determination of particle size distribution-sieving method. European Committee for Standardization, Brussels, Belgium.

Binder content

- ASTM D6307-16 (2016) Standard test method for asphalt content of hot-mix asphalt by ignition method, ASTM International, West Conshohocken, PA.

- ASTM D2172/D2172 M-17 (2017) Standard test methods for quantitative extraction of bitumen from bituminous paving mixtures, ASTM International, West Conshohocken, PA.

- EN 12697-1 (2012) Bituminous mixtures-test methods for hot mix asphalt-part 1: soluble binder content. European Committee for Standardization, Brussels, Belgium.

- EN 12697-39 (2012) Bituminous mixturestest methods for hot mix asphalt-part 39: binder content by ignition. European Committee for Standardization, Brussels, Belgium.

Fragmentation test

- ASTM D1557-12 (2012) Standard test methods for laboratory compaction characteristics of soil using modified effort [56,000 ft-lbf/ft3 (2700 $\mathrm{kN}-\mathrm{m} / \mathrm{m} 3)$ ], ASTM International, West Conshohocken, PA.

- EN 13286-2 (2012) Unbound and hydraulically bound mixtures-part 2: test methods for laboratory reference density and water contentproctor compaction. European Committee for Standardization, Brussels, Belgium.
- Recommendation of RILEM TC237-SIB on fragmentation test for recycled asphalt.

Cohesion test

- ASTM D6931-17 (2017) Standard test method for indirect tensile (IDT) strength of bituminous mixtures, ASTM International, West Conshohocken, PA.

- EN 12697-23 (2003) Bituminous mixtures. Test methods for hot mix asphalt. Determination of the indirect tensile strength of bituminous specimens. European Committee for Standardization, Brussels, Belgium.

- Recommendation of RILEM TC237-SIB on cohesion test for recycled asphalt.

\subsection{Mineral aggregates}

Aggregate size distribution (white curve)

- ASTM C136/C136 M-14 (2014) Standard test method for sieve analysis of fine and coarse aggregates, ASTM International, West Conshohocken, PA.

- EN 933-1 (2012) Tests for geometrical properties of aggregates-part 1: determination of particle size distribution-sieving method. European Committee for Standardization, Brussels, Belgium.

Specific gravity and absorption of fine aggregate

- ASTM C128-15 (2015) Standard test method for relative density (specific gravity) and absorption of fine aggregate, ASTM International, West Conshohocken, PA.

- EN 1097-6 (2013) Tests for mechanical and physical properties of aggregates. Determination of particle density and water absorption. European Committee for Standardization, Brussels, Belgium.

- EN 1097-7 (2008) Tests for mechanical and physical properties of aggregates-part 7: determination of the particle density of fillerpyknometer method. European Committee for Standardization, Brussels, Belgium. 
Index of aggregate particle shape and texture

- ASTM C1252-17 (2017) Standard test methods for uncompacted void content of fine aggregate (as influenced by particle shape, surface texture, and grading), ASTM International, West Conshohocken, PA.

- EN 933-3 (2012) Tests for geometrical properties of aggregates. Determination of particle shape. Flakiness index. European Committee for Standardization, Brussels, Belgium.

- EN 933-4 (2008) Tests for geometrical properties of aggregates. Determination of particle shape. Shape index. European Committee for Standardization, Brussels, Belgium.

\subsection{Bitumen}

Needle penetration

- ASTM D5/D5 M-13 (2013) Standard test method for penetration of bituminous materials, ASTM International, West Conshohocken, PA.

- EN 1426 (2007) Bitumen and bituminous binders-determination of needle penetration. European Committee for Standardization, Brussels, Belgium.

Softening point ring and ball

- ASTM D36/D36 M-14e1 (2014) Standard test method for softening point of bitumen (ringand-ball apparatus), ASTM International, West Conshohocken, PA.

- EN 1427 (2007) Bitumen and bituminous binders-determination of the softening point-ring and ball method. European Committee for Standardization, Brussels, Belgium.

\section{Definitions}

- Reclaimed asphalt material (RA) Conglomerate of particles made of aggregates, aged and oxidized bitumen and mastic of different sizes and shapes, obtained from the milling processes of old pavements.

- Black curve Sieve size distribution of the RA particles;
- White curve Sieve size distribution of the RA particles after bitumen extraction.

\section{Test procedure}

A set of properties are identified as significant for the characterization of RA material. They can be divided in three groups associated to the RA material as is, to the RA aggregate after bitumen extraction and to the extracted RA bitumen. For each of these three categories, a set of simple experimental characterization tests is proposed as shown in Fig. 1.

\subsection{RAP material}

The first part of the characterization protocol is devoted to the RA material in its original condition.

\subsubsection{Particle size distribution-black curve}

European and US sieving sizes and shapes can be used for the gradation analysis. Both dry and wet sieving procedure can be adopted. In the latter case, wet sieving process can be either carried out under running water or the particles are first washed and dry sieved, ensuring that the small particles, such as filler, are washed away and not sticking to larger aggregates.

In order to obtain what is conventionally known as "black curve", aggregate size analysis should be performed on RA after washing the material. As mentioned above there are two ways to determine the "black curve" after washing: method A and method B. In the method A, the RA material is washed with water over a $0.063 \mathrm{~mm}$ or $0.075 \mathrm{~mm}$ sieve to remove the finest particles in the range of filler [2, 3]. After washing, the retained RA material on the chosen wash sieve is dried at $30{ }^{\circ} \mathrm{C}$, and sieving and gradation are performed. Figure 2a shows the comparison between the sieve size analysis performed on RA before washing and after washing in reference to the method A. With the second approach $(\operatorname{method} B)$, the wet sieving of the RA is carried out under a continuous flow of water during all the sieving processes. Figure $2 b$ clearly shows that the method B could affect the grading curve on each sieve of the RA aggregate when compared to the method A. 
Fig. 1 Schematic of RA characterization protocol

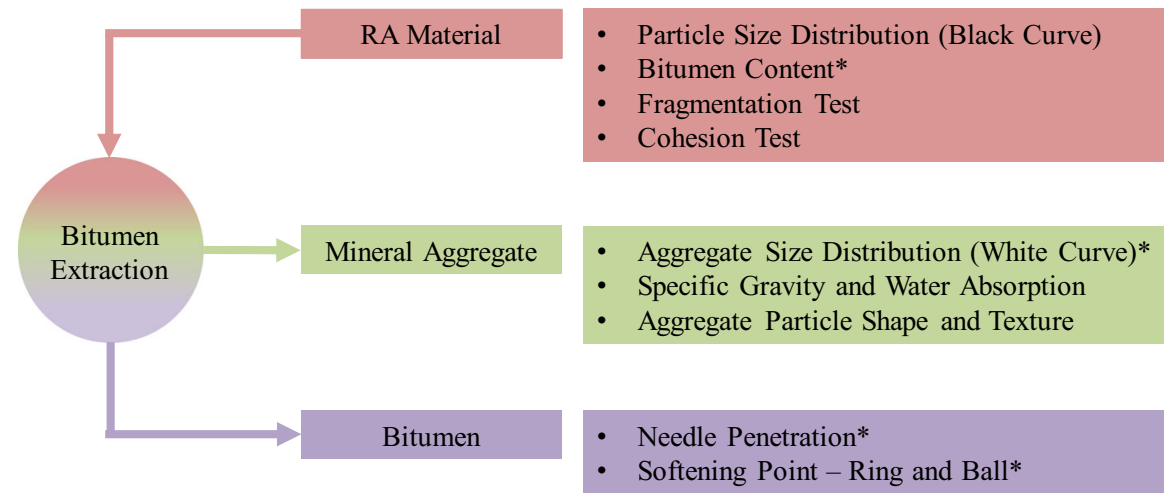

* These tests are carried out on several samples (at least 3 ) $n$ to determine the homogeneity of RAP

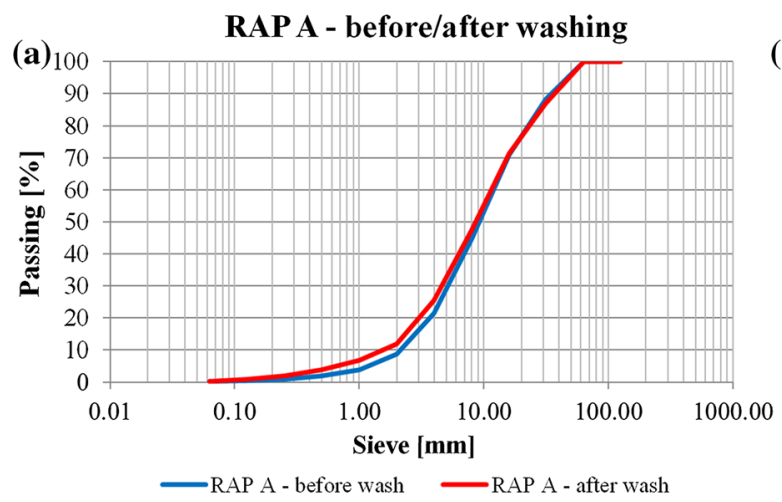

Fig. 2 Example of black curves before and after washing: a method A and $\mathbf{b}$ method B

Depending on the sieving parameters (frequency, amplitude, time), as well as the type of sieving apparatus and the temperature, the RA agglomerates are broken down to different extents. This may make the black curve difficult to reproduce unless the sieving parameters are specifically defined.

\subsubsection{Bitumen content}

Extraction and recovery of the bitumen from RA samples are performed according to the current international standards $[4,5]$ to determine the bitumen content expressed as percent of the weight of RAP and for further analysis of the bitumen properties (see Sect. 5.3 of the present document). Alternatively, the bitumen content can be estimated by the ignition method [6, 7]. However, using this procedure, the bitumen properties cannot be tested.

\subsubsection{Fragmentation test}

The fragmentation test measures the particle resistance to fragmentation under a series of shocks induced by dropping a steel mass, called a rammer, on a confined sample placed in a steel cylindrical mould. In this specific case, the modified Proctor test procedure [8, 9] is adopted to perform a series of impact tests on different sources of RA. Detailed explanation on the fragmentation test procedure can be found in a different RILEM recommendation entitled "Recommendation of RILEM TC237-SIB on fragmentation test for recycled asphalt".

\subsubsection{Cohesion test}

RAP material can be classified as "active" or "inactive", depending on the capacity of the residual bitumen to glue the particles together after 


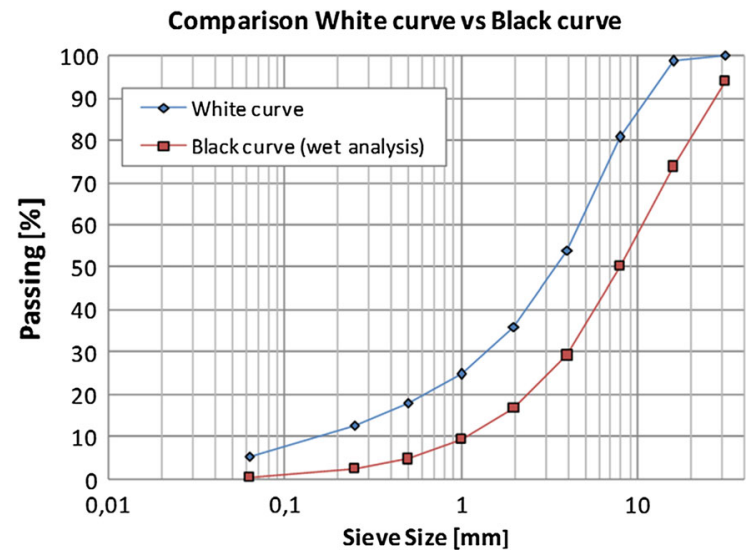

Fig. 3 Comparison between "black curve" and "white curve"; example for a specific RA material

compaction. The resulting cohesion is directly linked to the penetration of the aged binder and the compaction temperature. The experimental procedure and analysis of the cohesion test are detailed in a companion RILEM recommendation entitled "Recommendation of RILEM TC237-SIB on cohesion test for recycled asphalt".

\subsection{RAP mineral aggregates}

The second part of the characterization protocol addresses the properties of the RA mineral aggregates after bitumen extraction.

\subsubsection{Particle size distribution-white curve}

In addition to the particle size analysis of RA, the size distribution of the mineral particles contained in the recycled material must be determined after bitumen extraction and recovery. The aggregates obtained after binder recovering are used for aggregate size analysis (after washing) in order to determine the "white curve" of RA [2, 3]. In Fig. 3 "black curve" and "white curve" are compared as an example.

\subsubsection{Specific gravity and water absorption}

Particle density can be determined according to both EN 1097-6 [10], while the ASTM C127 and C128 standards $[11,12]$ can be selected to obtain the specific gravity (the density relative to water). These standards provide similar methods. For coarse aggregates, the the Archimedes' principle of buoyancy is used, while for fine aggregates specific gravity is measured indirectly through its volume in a calibrated pycnometer filled with solvent. This method is applicable also for coarse aggregates. At the same time, the water absorption and water content of RA or aggregate particles can be determined. Specific gravity itself is not a performance property, but is essential for the design of the aggregate composition. To obtain reasonable data it is necessary to determine the specific gravity on different fractions, at least on a fine (sand) and a coarse fraction.

Water content of RA is an important parameter both for hot and cold recycling and can be obtained based on the same two ASTM standards, C127 and C128, used for the specific gravity $[11,12]$. In cold recycling, the amount of water has to be taken into account for the calculation of the optimum water content for compaction. In hot recycling water evaporates in the mixing process and therefore has to be minimized to reduce unnecessary energy consumption.

\subsubsection{Aggregate particle shape and texture}

The aggregate particle shape and texture provides a quantitative measure of the aggregate shape and texture characteristics that may affect the performance of road and paving mixtures. These characteristics are measured with different methods according with EN $[13,14]$ and ASTM [15] standards only on aggregates. In Europe, the flakiness index (FI) is determined using bar sieves of half the maximum size of definite aggregate size fractions [13]. The FI is the relative amount passing the bar sieves and is a measure for the percentage of oblong particles. The shape index (SI) determines the percentage of non-cubicle particles and is defined as the dimensional ratio of length and thickness $\leq 3$ [14]. As the SI is measured on each particle visually and with the help of a particle slide gauge, only coarse aggregates larger than $4 \mathrm{~mm}$ can be measured. In the corresponding ASTM standard [15], the particle index is calculated using the voids of differently compacted dry aggregate particles.

\subsection{Bitumen}

The bitumen extracted from the RA needs to be tested according the following two test methods: 
- Needle penetration $[16,17]$.

- Softening point (ring and ball method) $[18,19]$.

These binder characteristics deliver a rough indication on the aging degree. However, for a proper assessment of the aging degree the binder characteristics of the virgin binder are needed. This is in general not possible, as the RA is a mixture of various asphalt types each produced with different binder grades. Nevertheless, it is an important property in hot recycling to determine the binder grade to be added and/or the amount of rejuvenating agent needed to decrease the viscosity of the hardened binder.

\subsection{RA material homogeneity}

The homogeneity of the RA material properties is critical for quality control of design asphalt mixtures containing recycled material. To verify the homogeneity of RA, a minimum of three different samples taken from the same RA stockpile need to be used to assess the homogeneity of the material source.

\section{Closing remark and test report}

This recommendation provides a simple protocol for the characterization of reclaimed asphalt (RA) that can be used for pavement application, with the objective of providing a material fingerprint that can support a more reliable asphalt mixture design process. Based on the present document the test report should contain:

- Relevant information on the tested RA material, such as origin, storing, and potential conditioning;

- The properties of the RA materials in terms of black curve, bitumen content, the results of the fragmentation and cohesion tests;

- The properties of the mineral aggregates of the RA materials, such as white curve, specific gravity, water absorption, aggregate particle shape and texture;

- The needle penetration and softening point of the extracted RA bitumen.

\section{Compliance with ethical standards}

Conflict of interest The authors declare that they have no conflict of interest.

\section{References}

1. Hansen K, Newcomb D, Cervarich M (2011) Asphalt tops the charts for environmental stewardship-again. Asph Pavement Mag NAPA 16(5):20-25

2. ASTM C136, C136 M-14 (2014) Standard test method for sieve analysis of fine and coarse aggregates. ASTM International, West Conshohocken

3. EN 933-1 (2012) Tests for geometrical properties of aggregates - part 1: determination of particle size distribution-sieving method. European Committee for Standardization, Brussels

4. ASTM D2172, D2172 M-17 (2017) Standard test methods for quantitative extraction of bitumen from bituminous paving mixtures. ASTM International, West Conshohocken

5. EN 12697-1 (2012) Bituminous mixtures-test methods for hot mix asphalt-part 1: soluble binder content. European Committee for Standardization, Brussels

6. ASTM D6307-16 (2016) Standard test method for asphalt content of hot-mix asphalt by ignition method. ASTM International, West Conshohocken

7. EN 12697-39 (2012) Bituminous mixtures - test methods for hot mix asphalt-part 39: binder content by ignition. European Committee for Standardization, Brussels

8. ASTM D1557-12 (2012) Standard test methods for laboratory compaction characteristics of soil using modified effort $\left(56,000 \mathrm{ft}-\mathrm{lbf} / \mathrm{ft}^{3}\left(2,700 \mathrm{kN}-\mathrm{m} / \mathrm{m}^{3}\right)\right)$. ASTM International, West Conshohocken

9. EN 13286-2 (2012) Unbound and hydraulically bound mixtures-part 2: test methods for laboratory reference density and water content-proctor compaction. European Committee for Standardization, Brussels

10. EN 1097-6 (2013) Tests for mechanical and physical properties of aggregates. Determination of particle density and water absorption. European Committee for Standardization, Brussels

11. ASTM C127-15 (2015) Standard test method for relative density (specific gravity) and absorption of coarse aggregate. ASTM International, West Conshohocken

12. ASTM C128-15 (2015) Standard test method for relative density (specific gravity) and absorption of fine aggregate. ASTM International, West Conshohocken

13. EN 933-3 (2012) Tests for geometrical properties of aggregates. Determination of particle shape. Flakiness index. European Committee for Standardization, Brussels

14. EN 933-4 (2008) Tests for geometrical properties of aggregates. Determination of particle shape. Shape index. European Committee for Standardization, Brussels

15. ASTM C1252-17 (2017) Standard test methods for uncompacted void content of fine aggregate (as influenced by particle shape, surface texture, and grading). ASTM, West Conshohocken

16. EN 1426 (2007) Bitumen and bituminous binders-determination of needle penetration. European Committee for Standardization, Brussels

17. ASTM D5, D5 M-13 (2013) Standard test method for penetration of bituminous materials. ASTM International, West Conshohocken 
18. EN 1427 (2007) Bitumen and bituminous binders-determination of the softening point-ring and ball method. European Committee for Standardization, Brussels
19. ASTM D36, D36 M-14e1 (2014) Standard test method for softening point of bitumen (ring-and-ball apparatus). ASTM International, West Conshohocken 